\title{
Optimizing Tri-Core Permanent-Magnet-Linear-Generator Direct-Drive Wave-Energy-Conversion System Design for Sea Wave Characteristics in South Coast Yogyakarta
}

\author{
Fransisco Danang Wijaya, Sarjiya, Muhammad Rifa'i Putra Sugita \\ Departement of Electrical Engineering and Information Technology, Faculty of Engineering \\ Universitas Gadjah Mada, 2nd Grafika Street, Mlati, Sleman 55281, Yogyakarta, Indonesia
}

\begin{tabular}{ll}
\hline Article Info & ABSTRACT \\
\cline { 2 - 3 } Article history: & $\begin{array}{l}\text { According to statistical data, the south coast Yogyakarta has significant } \\
\text { ocean wave height which can be used to generate electricity by using wave- } \\
\text { energy-converter system. One of the simplest way to convert wave energy to } \\
\text { electricity is using direct-drive wave-energy-conversion (WEC) system with } \\
\text { Received Oct 24, } 2016\end{array}$ \\
$\begin{array}{l}\text { permanent-magnet-linear-generator (PMLG). This method is simple because } \\
\text { it does not need to convert linear motion to rotational motion. However, } \\
\text { Accepted Feb 19, } 2017\end{array}$ & $\begin{array}{l}\text { PMLG has large electric power losses, has great weight in both of the stator } \\
\text { and rotor, and expensive to make. In this paper, a tri-core PMLG was } \\
\text { designed. The electric power losses in the winding, translator weight, and } \\
\text { Keyword: }\end{array}$ \\
material cost were ideally minimized using multiobjective optimization \\
combined with simulated annealing (SA) algorithm. Then, the design was \\
Ocean waves
\end{tabular}

Copyright $@ 2017$ Institute of Advanced Engineering and Science. All rights reserved.

\author{
Corresponding Author: \\ Muhammad Rifa'i Putra Sugita, \\ Departement of Electrical Engineering and Information Technology, \\ Faculty of Engineering, \\ Universitas Gadjah Mada, \\ 2nd Grafika Street, Mlati, Sleman, Yogyakarta, Indonesia 55281. \\ Email: muhammad.rifai.p@mail.ugm.ac.id
}

\section{INTRODUCTION}

One of the world's renewable energy resources which available in a great amount is ocean waves energy. It is estimated that the total ocean waves energy in the world can be used to fulfill $2 \%$ from the world's total energy demand [1]. According to [2], south coast of Yogyakarta has potential to generate electric power about 1.9 MW. This is also supported based on the mapping result which conducts by Indonesian Agency for Meteorology Climatology and Geophysics that south coast of Yogyakarta has average ocean waves between 0.5 - 2 meters height [3]. It means that south coast of Yogyakarta has vertical velocity of the ocean waves about $0.5 \mathrm{~m} / \mathrm{s}$ [4]. This velocity is able to make motion which can drive a generator.

There are several technology of wave-energy-conversion (WEC) system. One of the simple way to convert the ocean waves to electricity is using direct-drive WEC system technology [5]. Direct-drive WEC system is simple because it doesnot require to convert linear motion of the ocean waves to rotational motion to generate electricity, so the efficiency of the WEC is higher [6]. It happens because direct-drive WEC is using floater (buoy) coupled with linear generator to convert ocean waves motion into electricity, so that it is 
only needs a few part to develop the WEC. Linear generator which is used to convert the linear motion of the ocean waves is classified based on the shape, that is: tubular, tri-core, square-core and tri-coil linear generator [7], [8]. Tri-core linear generator is cheaper, provide higher emf, and suitable with ocean waves between 0.5 until 1.5 meters height which is similar to the characteristic of ocean waves in south coast of Yogyakarta rather than the others linear generator topologies.

To obtain a good design of linear generator, an optimization procedure should be done to get global optimal solutions [9], [10]. Based on the literature review, there are still only a few research which related to the optimization of linear generator design, although the optimization procedure has been succesfully used to optimize several electric machine, such as transformer, direct-current machine, synchronous machine, and the others electric machine [11-14]. Result was shown that optimization procedure could deliver better electric machine design rather than without optimization procedure.

This research proposes direct-drive WEC applied with tri-core permanent-magnet-linear-generator (PMLG) for converting ocean waves motion to electricity.To get a good design of PMLG, the optimization was performed in this linear generator. Three objectives function was used in this optimization, there are: electric power losses in the winding, translator weight, and material cost of the PMLG. That three objectives function then minimized using simulated annealing (SA) algorithm to get the best design. Then, the overall design of the PMLG was verivied using finite element analysis (FEA) to get some parameters of the linear generator which could not be calculated analytically and to confirmed the magnetic parameter of the PMLG. Finally, the optimized design of tri-core PMLG was simulated using sinusoidal ocean waves characteristic to analyze and investigate the performance of the linear generator if the PMLG installed in south coast of Yogyakarta.

\section{RESEARCH METHOD}

\subsection{Nomenclature}

$R_{w}$ internal resistance of AWG $11(\mathrm{ohm} / \mathrm{m}), P_{d t}$ expected power of PMLG (watt), $m$ number of phase, $\mu$ magnetic permeability, $M_{s}$ number of armature, $A_{c}$ area of the coil $\left(\mathrm{m}^{2}\right), K_{c u}$ winding filling factor, $D_{w}$ wire diameter $(\mathrm{m}), C_{m}$ air gap flux density coefficient, $K_{c}$ Carter's coefficient, $B_{g}$ air gap flux density (T), $B_{r}$ permenent magnet residual flux $(\mathrm{T}), H_{c}$ magnetic flux coercive.

\subsection{Site Selection for Installing Direct-Drive WEC}

As mentioned above, the south coast of Java Island, especially in the south coast of Yogyakarta has large potential of ocean waves energy. According to the monthly data which has beencollected by IndonesianAgency for Meteorology Climatology and Geophysicsfrom 2000 until 2010, in this location, the significant wave height has average value of 1.44 meters. From that data, the WEC system was designed to work in rated condition with 1 meters wave height, so that the WEC could work well throughout the year.

$$
v_{S}(t)=\omega \cdot \frac{H_{S}}{2} \cos (\omega t)
$$

Using Equation (1), where angular velocity of the ocean wave $(\omega)$ was $1.76 \mathrm{rad} / \mathrm{s}$, significant wave height $\left(H_{s}\right)$ was $1 \mathrm{~m}$, and ocean wave period was $3.55 \mathrm{~s}$, so that the average vertical velocity of the ocean waves $\left(v_{s}\right)$ was $0.6 \mathrm{~m} / \mathrm{s}$. It was assumed that the linear velocity of linear generator was the same as vertical velocity of the ocean waves since the direct-drive WEC became wave followers [15].

\subsection{Mathematical Model of Tri-Core PMLG}

Permanent-magnet-linear-generator (PMLG) with tri-core topology is one of the linear generator type which has triangular shape core in both of the stator and translator as shown in Figure 1(a).The design parameters of tri-core PMLG was shown in Figure 1(b). The aim of this shape was to simplify manufacturing process because of the simple shape and construction, so that it would minimizethe manufacturing cost.

There are several mathematical models of tri-core PMLG which derived from the magnetical Equation of linear generator [16]. This mathematical models then optimized, so a good design of tri-core PMLG was obtained. The mathematical models are as follows:

1) Electrical current produced by PMLG $\left(i_{p h}\right)$ : from the expected power and emf produced by PMLG $\left(E_{p h}\right)$, the Equation to determine the electrical current is given by

$$
i_{p h}=\frac{P_{d t}}{m E_{p h}}
$$


2) Winding resistance $\left(R_{p h}\right)$ : per phases winding resistance is influenced by internal resistance and length of wire $\left(L_{c}\right)$, the Equation is as follows below

$$
R_{p h}=R_{w} L_{c} N_{p h}
$$

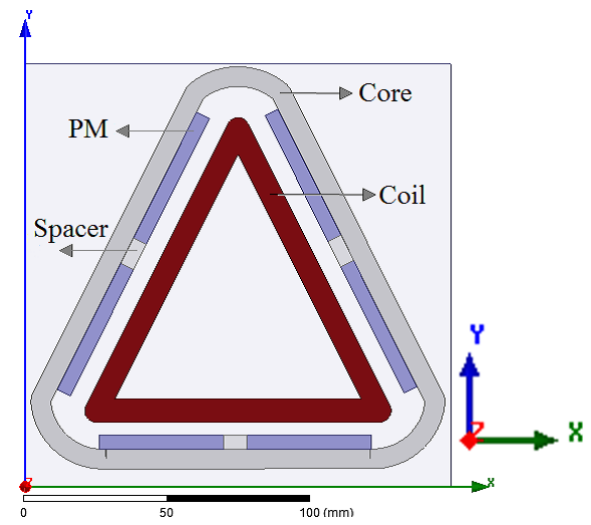

(a)

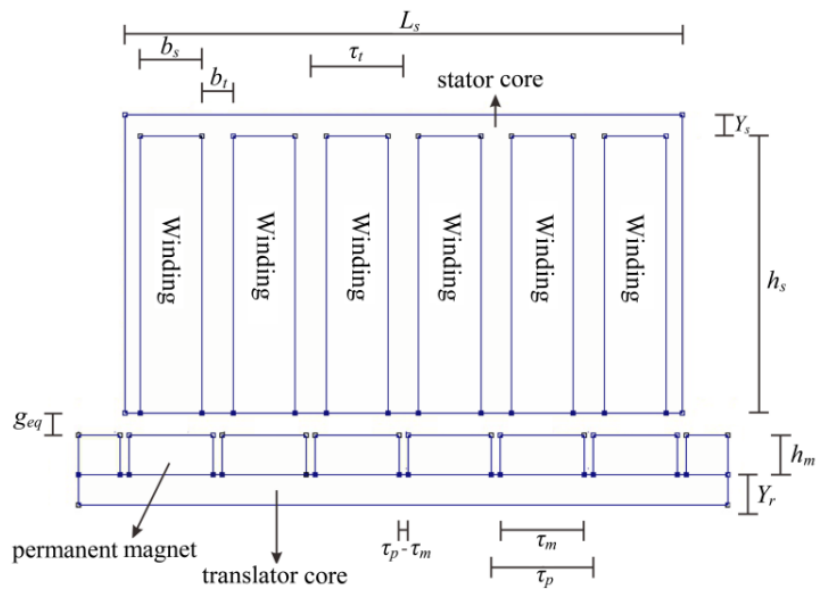

(b)

Figure 1. (a) Tri-core PMLG structure [8]; (b) Design parameters of tri-core PMLG [4]

where $N_{p h}$ is number of turns per phase which is derived from number of turns per slot $N_{c}$. The Equation is shown by (4) and (5) respectively

$$
\begin{aligned}
& N_{p h}=N_{c} p q \\
& N_{c}=\frac{A_{c} K_{c u}}{\pi\left(D_{w} / 2\right)^{2}}
\end{aligned}
$$

3) Geometry of tri-core PMLG: the geometry of tri-core PMLG will affect the phase resistance which also related to the electrical power losses in the winding, overall weight, and material cost needed to construct the linear generator. The mathematical geometry model of tri-core PMLG is mentioned in (6)-(11) with some of the nomenclature is mentioned in the next chapter.

$$
\begin{aligned}
& A_{c}=h_{s} b_{s} \\
& L_{c}=2 \pi\left(Y_{S}+\frac{h_{s}}{2}\right)+M_{s} W_{s} \\
& K_{c}=\frac{\tau_{t}\left(5 g+b_{s}\right)}{\tau_{t}\left(5 g+b_{s}\right)-b_{s}^{2}} \\
& g_{e q}=K_{c} \cdot g \\
& h_{m}=\frac{g_{e q} B_{g} B_{r}}{\mu_{o}\left|H_{c}\right|\left(B_{r}-B_{g}\right)}
\end{aligned}
$$




$$
\tau_{m}=C_{m} \tau_{p}
$$

\subsection{Optimization Procedure using Simulated Annealing}

The design optimization of tri-core PMLG was done using multiobjectives function such as: electric power losses in the winding, translator weight, and material cost of the PMLG. Then, besause the use of more than one single objectives function, so all of the objectives function must be transformed to a single objectives function using weighted sum approach. The method worked by using some weighted value $w_{1}, w_{2}$, $w_{3}, \ldots w_{n}$ with $w_{1}+w_{2}+w_{3} \ldots+w_{n}=1$. Each of the objective function was multiplied with the weighted value, the Equation for transforming the multiobjectives function to a single objectives function was shown below

$$
F_{t}=\sum_{i=1}^{n} w_{i} F_{i}
$$

where, $w_{i}$ is the weighted value of the objectives function, $F_{i}$ is each of single objectives function and $F_{t}$ was the total single objectives function. Each of the objectives function was mentioned below:

1) Electrical power losses in the winding $\left(P_{l o s s}\right)$ : the electrical power losses in the winding was influenced by winding resistance, the Equation of the first objectives function was given by

$$
F_{1}=P_{\text {loss }}=i_{p h}^{2} R_{p h}
$$

2) Translator weight $\left(m_{t r}\right)$ : translator of the tri-core PMLG consisted of permanent magnet and translator core, to minimize the translator weight, the weight of permanent magnet and translator core must be minimized. The Equation was mentioned below respectivelly

$$
F_{2}=m_{t r}=m_{p m}+m_{t c}
$$

where $m_{p m}$ is permanent magnet weight and $m_{t c}$ is the translator core weight. Each of the component could be calculated using Equation as mentioned below

$$
\begin{aligned}
& m_{p m}=\left(\rho_{m} M_{s} h_{m} \tau_{m} W_{s} L_{t}\right) /\left(\tau_{m}+\frac{\left(\tau_{p}-\tau_{m}\right)}{2}\right) \\
& m_{t c}=\rho_{t c} M_{s} Y_{r} L_{t}\left(W_{s}+2\left(h_{m}+g_{e q}\right)\right)
\end{aligned}
$$

where $\rho_{m}$ is the mass density of permanent magnet, $\rho_{t c}$ is the mass density of translator core, and $L_{t}$ is translator length which was designed to be 1 meters.

3) Material cost of the PMLG $\left(c_{t o t}\right)$ : the material cost of tri-core PMLG consisted of: cost for both of translator and stator core, cost for permanent magnet, and cost for coper wire. Cost function could be calculated using weight of each part of the generator and the price per kilograms according to [17]. The Equation for calculating coper weight and stator core weight was mentioned below

$$
\begin{aligned}
& m_{c u}=\rho_{c u} \pi\left(r_{\text {wire }}\right)^{2} L_{c} N_{p h} \\
& m_{s c}=\rho_{s c} M_{s} W_{s}\left(\left(\left(h_{s}+Y_{s}\right) L_{s}\right)-\left(b_{s} h_{s} p q m\right)\right)
\end{aligned}
$$

where $\rho_{c u}$ is the mass density of coper wire, $\rho_{s c}$ is the mass density of stator core. Then the material cost of tricore PMLG could be calculated using Equation (10).

$$
F_{3}=c_{t o t}=m_{p m p m}{ }^{p}+\left(m_{t c}+m_{s c}\right) c_{f e}+m_{c u}{ }^{c} c u
$$


where $c_{p m}$ is permanent magnet cost per kilogram, $c_{f e}$ is steel cost per kilogram, and $c_{c u}$ is coper cost per kilogram.

\section{RESULTS AND ANALYSIS}

\subsection{Optimizing Tri-Core PMLG Design}

It was decided to designa pico-scale tri-core PMLG with three-phase wye configuration and the expected output power is $1 \mathrm{~kW}$. Several initial parameters were used in the design process, such as: average translator speed to be $0.6 \mathrm{~m} / \mathrm{s}$, the use of AWG 11 wire, and $\mathrm{NdFeB}$ permanent magnet to constructed the linear generator. AWG 11 wire was choosenbecause the expected power of the generator was in pico-scale, so the current that flow through the winding was not exceed the current capability of AWG 11 which was 12 A. Then, NdFeB 52 MGOe was used because this type of permanent magnet has large flux density rather than the others type, so it would generate higher electromotive force (emf). With the same generated power, the higher emf woulddecrease the current generated from the PMLG, so it would decrease the electrical power losses in the winding. The $\mathrm{NdFeB}$ permanent magnet wasmounted in the translator core surface.

Table 1. Specification of Tri-Core PMLG

\begin{tabular}{|c|c|c|c|}
\hline \multirow[b]{2}{*}{ Variables } & \multirow[b]{2}{*}{ Symbol } & \multicolumn{2}{|c|}{ Values } \\
\hline & & $\begin{array}{c}\text { Analytical } \\
\text { Design }\end{array}$ & $\begin{array}{l}\text { Optimized } \\
\text { Design }\end{array}$ \\
\hline Stator width $(\mathrm{mm})$ & $W_{s}$ & 50 & 50 \\
\hline Number of slot per pole per phase & $q$ & $1 / 3$ & $1 / 3$ \\
\hline Number of poles & $p$ & 12 & 12 \\
\hline Average flux density in air gap (T) & $B a v$ & 0.8 & 1 \\
\hline Air gap (mm) & $g$ & 2 & 0.4 \\
\hline Flux density in the stator yoke (T) & Bys & 1.8 & 2.2 \\
\hline Flux density in the rotor yoke $(\mathrm{T})$ & Byr & 1.2 & 2 \\
\hline Stator length (mm) & $L_{s}$ & 148.68 & 313.4 \\
\hline Pole-pitch (mm) & $\tau_{p}$ & 12.4 & 26.1 \\
\hline Tooth-pitch (mm) & $\tau_{t}$ & 12.4 & 26.1 \\
\hline Stator slot width (mm) & $b_{s}$ & 8.26 & 17.41 \\
\hline Stator tooth width (mm) & $b_{t}$ & 4.1 & 8.7 \\
\hline Real air gap (mm) & $g_{e q}$ & 2.86 & 1 \\
\hline Permanent magnet thickness (mm) & $h_{m}$ & 5.17 & 3.66 \\
\hline Permanent magnet length (mm) & $\tau_{m}$ & 11.2 & 23.5 \\
\hline Stator yoke thickness (mm) & $Y_{s}$ & 2.75 & 5.93 \\
\hline Rotor yoke thickness (mm) & $Y_{r}$ & 4.13 & 6.53 \\
\hline Slot height (mm) & $h_{s}$ & 217 & 60 \\
\hline Number of stator turns per slot & $N_{c}$ & 258 & 150 \\
\hline Number of stator turns per phase & $N_{p h}$ & 1031 & 600 \\
\hline Average length of stator wire per turn (mm) & $L_{c}$ & 849 & 375.8 \\
\hline Weight of permanent magnet $(\mathrm{kg})$ & $m_{p m}$ & 0.8 & 1.188 \\
\hline Weight of core $(\mathrm{kg})$ & $m_{f e}$ & 19.1 & 18.21 \\
\hline Weight of copper $(\mathrm{kg})$ & $m_{c u}$ & 27.67 & 7.13 \\
\hline Cost for permanent magnet $(\$)$ & $C_{p m}$ & 36.87 & 54.92 \\
\hline Cost for core $(\$)$ & $C_{f e}$ & 75.3 & 72.12 \\
\hline Cost for copper $(\$)$ & $C_{c u}$ & 365.3 & 94.21 \\
\hline Winding resistance (ohm) & $R_{p h}$ & 3.62 & 0.93 \\
\hline Emf (volt rms) & $E_{p h}$ & 58.34 & 42.52 \\
\hline Max coil current $(\mathrm{A})$ & $i_{p h}$ & 5.7 & 7.84 \\
\hline Electrical frequency $(\mathrm{Hz})$ & $f$ & 24.2 & 11.49 \\
\hline Winding power losses (watt) & $P_{\text {loss }}$ & 354.3 & 172.2 \\
\hline Efficiency $(\%)$ & $\eta$ & 64.57 & 82.78 \\
\hline
\end{tabular}

Table 1 showed comparison between analytical and optimized design specification of tri-core PMLG. The optimized design of tri-core PMLG wasdelivered using simulated annealing algorithm combined with objective function which had been mentioned in (13)-(19) and several mathematical Equation of PMLG 
design mentioned in (2)-(11). The weighting factor to optimize tri-core PMLG design had chosen to be 0.2 for weighting the electrical power losses objectives function, 0.7 for weighting the translator weight objectives function, and 0.1 for weighting the material cost objectives function.This weighting value was chosenbecause it could deliver the most optimum design of tri-core PMLG rather than the other weighting value. As seen in Table 1, the optimized design delivered lower winding resistance compared to the analytical design, it wouldgive effect to the electrical power losses in the winding, so that the efficiency of the optimized design result of tri-core PMLG was higher compared to the analytical design result. Then, thetranslator weight delivered from optimization process was $10.16 \mathrm{~kg}$, and it was less higher than the analytical result which gave $7.12 \mathrm{~kg}$, it was due to the spreading of weighting value, so that all of the objectives function was in the optimum value. However, the overall weight of PMLG drawn from optimization result gave a great different. The overall weight from optimization result was $26.53 \mathrm{~kg}$, but the analytical result gave $47.48 \mathrm{~kg}$. This overall weight affected the material cost of tri-core PMLG, the material cost needed by optimized design was $\$ 221.3$, but the analytical result needed $\$ 477.3$ to build tri-core PMLG. It hass been shown that optimization procedure succesfully gives tri-core PMLG with optimum design specification.

\subsection{Optimized Tri-Core PMLG Design Verification using FEA}

The use of FEA was to analyze the two dimensional magnetic phenomenon in the optimized design, including to show unknown parameters which could not be determined using mathematical Equation such as winding inductance. It happened because FEA can deliver more accurate magnetical model result due to the use of differential Equation in magnetic field model. From the simulation result drawn from FEMM software, the maximum flux in the stator yoke was $1.83 \mathrm{~T}$ and the maximum flux in the translator yoke was $2.1 \mathrm{~T}$. The magnetical flux in the translator yoke was larger than the assumption, but it wasacceptable since the maximum flux only happened in a small area, so it did not make the translator yoke became excessive saturation.Another result delivered from FEMM showedthat the phase inductance of tri-core PMLG was $0.049 \mathrm{H}$, this value was used to simulate and analyze the performance of tri-core PMLG in dynamic condition. Figure 2 shows flux density distribution in optimized tri-core PMLG design

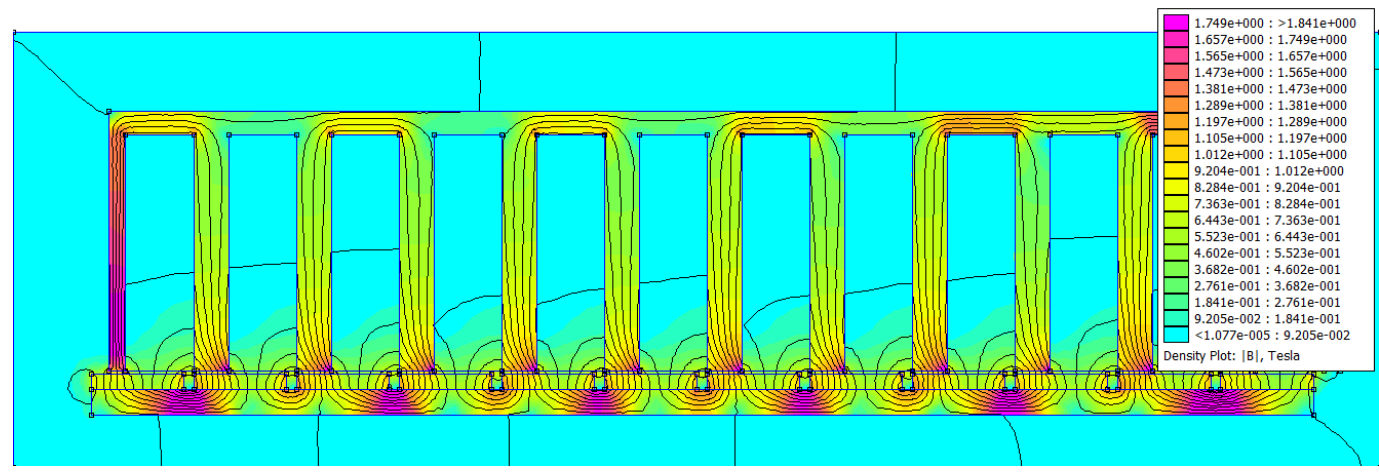

Figure 3. Flux density distribution in optimized tri-core PMLG design

\subsection{Electrical Characteristic of PMLG}

To analyze the performance of tri-core PMLG, a Simulink/MATLAB had been build. The first was to analyze the effect of load resistance to the output power and efficiency of tri-core PMLG. Simulation was conducted by varying load resistance of tri-core PMLG from 0 until $50 \mathrm{ohms}$ with $1 \mathrm{ohm}$ step size, and the translator speed was set to $0.6 \mathrm{~m} / \mathrm{s}$. Figure 4(a) showed the simulation result. As seen, the maximum output power was 589 watt, and it happened in $4 \mathrm{ohms} \mathrm{load}$. The input power of the generator was 726 watt, so that since the mechanical power losses and core losses was neglected, the maximum efficiency of tri-core PMLG was $81.14 \%$. This value was closest with the efficiency calculated in optimized design of PMLG.

When the optimal load was connected to the tri-core PMLG, the output characteristic of PMLG showed in Figure 4(b). It showed that the current waslagging to the emf produced by tri-core PMLG, it happened because of the phase inductance which present in the PMLG winding. However, the terminal voltage was in phase with the terminal current because of the resistive load. In the optimum load condition, the phase terminal voltage typically had a great different with the phase emf due to the resistance value of the PMLG. When the load resistance was increasing, the terminal voltage would also be increasing near the emf, 
but when the load resistance was not in optimal value, the output power generated by PMLG was decreasingas shown in Figure 4(a).

In fact, the ocean waves never happened in a steady state condition. Usually the characteristic of the ocean waves was assume to be sinusoidal waves with a certain height and period. This condition made the translator speed changed sinusoidally, and it gave effect to the phase emf, phase current, and phase terminal voltage. The simulation result using sinusoidal ocean waves with constant height and period was shown in Figure 5(a). As seen, the peak magnitude of the emf changed sinusoidally according to the ocean waves movements. Since the vertical ocean wave speed changed sinusoidally, the input and output power of tri-core PMLG was represented in Figure 5(b). The peak input power of tri-core PMLG was 1,122 watt and the peak output power of tri-core PMLG was911 watt. This value was near the expected value of initial design parameters of the generator. The input and output power of tri-core PMLG increased when the vertical ocean waves speed was increasing due to the increase of wave height. The effect of ocean wave height to the output power of tri-core PMLG was shown in Table 2. It has been shown that the generated output power of PMLG is intermittent since the ocean waves height is changed periodically.

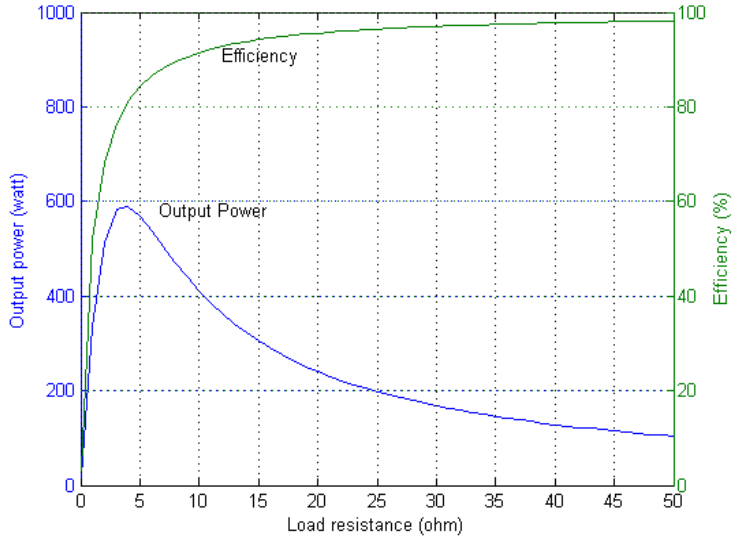

(a)

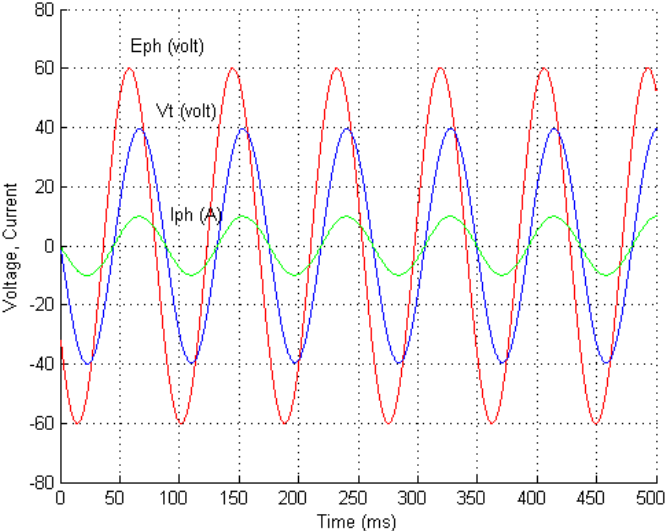

(b)

Figure 4. (a) Effect of load resistance to the output power and efficiency of tri-core PMLG; (b) Output characteristic of tri-core PMLG in steady state condition

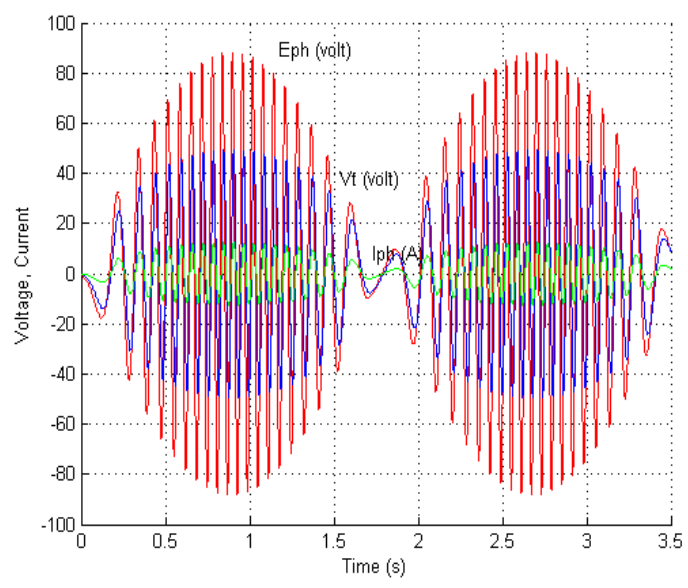

(a)

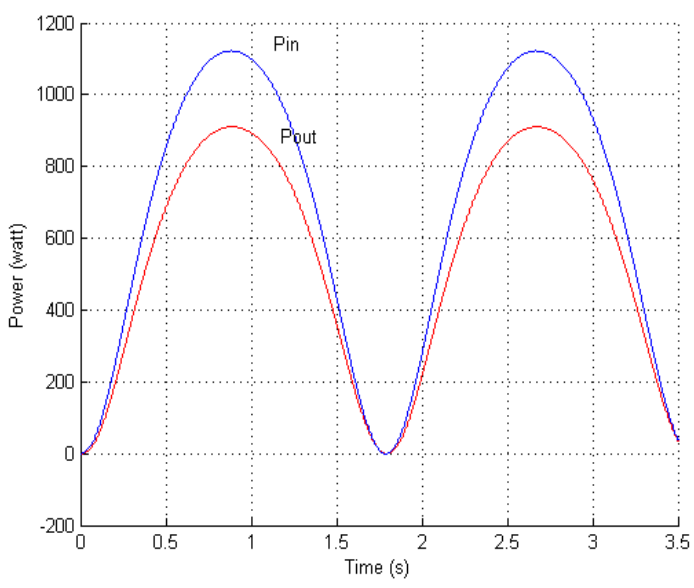

(b)

Figure 5. (a) Output characteristic of tri-core PMLG in sinusoidal ocean waves; (b) Input and output power of tri-core PMLG 
Table 2. Effect of ocean wave height to the output of PMLG

\begin{tabular}{lccccccc}
\hline Wave height (m) & 0.2 & 0.5 & 1 & 1.5 & 2 & 2.5 & 3 \\
\hline Peak output power (watt) & 310 & 628 & 911 & 1083 & 1197 & 1277 & 1334 \\
Peak phase emf (V) & 38.81 & 63.09 & 88.16 & 108.1 & 125.2 & 140.2 & 153.18 \\
Peak phase terminal volatge (V) & 28.59 & 40.9 & 49.22 & 53.72 & 56.46 & 58.33 & 59.57 \\
Peak phase current (A) & 7.15 & 10.23 & 12.3 & 13.43 & 14.11 & 14.58 & 14.89 \\
Frequency (Hz) & 5.75 & 7.66 & 11.49 & 13.4 & 15.33 & 17.24 & 19.16 \\
Peak power losses (W) & 72 & 145 & 211 & 252 & 278 & 297 & 313 \\
Efficiency (\%) & 81.2 & 81.2 & 81.2 & 81.1 & 81.2 & 81.1 & 81.0 \\
\hline
\end{tabular}

\section{CONCLUSION}

A small scale of wave-energy-conversion system has been designed and optimized using simulated annealing algorithm. From the optimization process, a good design of tri-core PMLG which has low electrical power losses in the winding, low translator weight, and low material cost has been obtained. The optimized design of tri core PMLG can generate 911 watt peak output power at the rated condition and at the optimum load with $81.14 \%$ efficiency. It has been shown since the translator is light in weight, the buoy will easily follows the ocean wave motion, it also happens in translator because the buoy and the translator is coupled. Furthermore, this condition will make the generator more easily to produce electrical power, rather than the PMLG which has heavy translator. Then, since the south coast of Yogyakarta is wavy and support the formation of waves between 0.5 to 1.5 meters height, the optimized design of PMLG is suitable for direct-drive WEC with low power losses and cost to install.

\section{REFERENCES}

[1] J Faiz and M Ebrahimi-Salari, "Design and Simulation of a $250 \mathrm{~kW}$ Linear Permanent Magnet Generator for Wave Energy to Electric Energy Conversion in Caspian Sea", Sustainable Power Generation and Supply, 2009. SUPERGEN '09. International Conference on, pp. 1-6, April 2009.

[2] Rahma S, "The potential study of ocean wave power plant using oscillating water column system in thirty Indonesian maritime territory", Universitas Indonesia, Jakarta, Thesis Report 2010.

[3] Susilohadi, "Mapping of Ocean Energy in Indonesia", 2013, pp. 1-32.

[4] Muhammad R.P.S, F.D Wijaya, and Sarjiya, "Design and Analysis of Tri Core Permanent Magnet Linear Generator for Wave Energy Conversion in South Coas of Java Island", 6th International Annual Engineering Seminar, pp. 1-6, August 2016.

[5] Hosna Titah Benbouzid and Mohamed Benbouzid, "Ocean wave energy extraction: Up-to-date technologies review and evaluation", 2014 International Power Electronics and Application Conference and Exposition (PEAC), November 2014.

[6] Iraide Lópeza, Jon Andreua, Salvador Ceballosb, Iñigo Martínez de Alegríaa, and Iñigo Kortabarriaa, "Review of wave energy technologies and the necessary power-equipment", Renewable and Sustainable Energy Reviews, vol. 27, pp. 413-414, 2013.

[7] M.A.F.M. Hamim, T Ibrahim, and N.M. Nor, "Design of Portable Pico Linear Permanent Magnet Generator for Wave Energy Conversion", Information Technology and Electrical Engineering (ICITEE), pp. 1-4, 2014.

[8] A.H. Memon, T. Bin Ibrahim, and N. Perumal, "Portable and pico-scale linear generator for wave energy conversion", Intelligent and Advanced Systems (ICIAS), 2014 5th International Conference on, pp. 1-4, 2014.

[9] Yuxin Sun, Qinghua Wu, and Xuesong Yan, "An Improved Constrained Engineering Optimization Design Algorithm", TELKOMNIKA Indonesian Journal of Electrical Engineering, vol. 12, no. 11, pp. 7079-7978, 2014.

[10] Qinghua Wu and et al, "Research of Function Optimization Algorithm", TELKOMNIKA Indonesian Journal of Electrical Engineering, vol. 10, no. 4, pp. 858-863, 2012.

[11] N Bianchi and S. Bolognani, "Design optimisation of electric motors by genetic algorithms", IEE Proceedings Electric Power Applications, vol. 145, no. 5, pp. 475-483, September 1998.

[12] Amit Kumar Yadav and et al, "Design Optimization of High-Frequency Power Transformer by Genetic Algorithm and Simulated Annealing", International Journal of Electrical and Computer Engineering (IJECE), vol. 1, no. 2, pp. 102-109, 2011.

[13] Reza Ilka and S. Asghar Gholamian, "Optimum Design of a Five-Phase Permanent Magnet Synchronous Motor for Underwater Vehicles by use of Particle Swarm Optimization", TELKOMNIKA Indonesian Journal of Electrical Engineering, vol. 10, no. 5, pp. 925-932, 2012.

[14] Hany M. Hasanien, "Particle Swarm Design Optimization of Transverse Flux Linear Motor for Weight Reduction and Improvement of Thrust Force", IEEE Transactions on Industrial Electronics, vol. 58, no. 9, pp. 4048-4056, September 2011.

[15] Ean A Amon, Ted K. A. Brekken, and Alphonse A. Schacher, "Maximum Power Point Tracking for Ocean Wave Energy Conversion", IEEE Transactions on Industry Applications, vol. 48, no. 3, pp. 1079 - 1086, March 2012.

[16] Rajkumar Parthasarathy, "Linear PM Generator For Wave Energy Conversion", Thesis in Louisiana State University and Agricultural and Mechanical College, 2012. 
[17] Ozan Keysan and et al, "A direct drive permanent magnet generator design for a tidal current turbine (SeaGen)", 2011 IEEE International Electric Machines \& Drives Conference (IEMDC), pp. 224-229, May 2011

[18] Kondapalli Siva R.R and Azrul Hisham B.O, "Design Optimization of A BLDC Motor by Genetic Algorithm and Simulated Annealing", International Conference on Intelligent and Advanced Systems, pp. 854-858, 2007.

\section{BIOGRAPHIES OF AUTHORS}

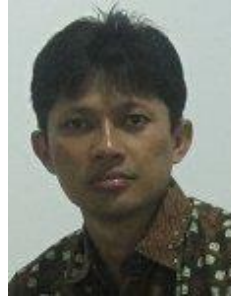

Fransisco Danang Wijaya was born on February 1974 in Sleman, Indonesia. He received his Bachelor and Master degree, both from Electrical Engineering Major, Gadjah Mada University in 1997 and 2001 respectively. He then got his Doctor of Engineering in Tokyo Institute of Technology in 2009. He is currently Associate Professor at the Department of Electrical Engineering and Information Technology, Gadjah Mada University. His research is specialized in power system engineering, energy conversion, also transmission and distribution system. He is also expert in power system control technique using Magnetic Energy Recovery Switch (MERS).

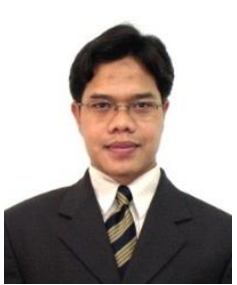

Sarjiya received the bachelor and master degrees from Gadjah Mada University, Yogyakarta, Indonesia, in 1998 and 2001, respectively, and the Ph.D. degree from the Chulalongkorn University, Thailand, in 2008, all in electrical engineering. Presently, he joint with the Electrical Engineering and Information Technology Department at Gadjah Mada University. His research interests include reliability evaluation of electric power systems, economic and secure operation of electric power systems, power systems and energy planning, and renewable energy integration.

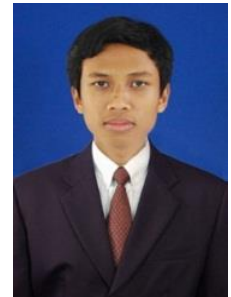

Muhammad Rifa'i Putra Sugita was born in Bantul, special district of Yogyakarta in 1993. He received Bachelor Engineering degree in Department of Electrical Engineering and Information Technology, Faculty of Engineering, Universitas Gadjah Mada in 2016. He is currently an M.Eng. students in the same department. His research interest include renewable energy from ocean waves, hybrid energy, optimization technique, dissolved gas analysis in power transformer, distributed generation, and smart grid application. 